\title{
Perfil epidemiológico do uso de medicamentos entre estudantes universitários
}

\author{
Epidemiological profile of drug use among university students
}

Perfil epidemiológico del consumo de drogas en estudiantes universitarios

Victor Manoel Pereira da Silva ${ }^{1 *}$, Henry Johnson Passos de Oliveira ${ }^{2}$, Williany Kettly de Souza ${ }^{1}$, Darli Maria de Souza ${ }^{2}$, Jéssica Ariel Rodrigues de Santana ${ }^{1}$, Stephany Paula da Silva Canejo ${ }^{1}$, Rayane de Paula Lima de Lins ${ }^{2}$, Francisca Bianca de Almeida Brito ${ }^{1}$, Jessica Mirelly Rosendo Lira ${ }^{1}$, Lucas de Lima Seixas Santana ${ }^{1}$.

\section{RESUMO}

Objetivo: Evidenciar o perfil epidemiológico da utilização de fármacos pelos estudantes da escola de saúde de um centro universitário privado. Métodos: Trata-se de um estudo de caráter descritivo, transversal, com abordagem quantitativa, realizado com os alunos dos cursos de saúde de um centro universitário privado da região nordeste do Brasil. Como instrumento para coleta de dados foi desenvolvido um questionário com (16) dezesseis perguntas sobre as características demográficas, sociais e culturais referentes a automedicação. Resultados: Foi evidenciado que a maior frequência dos participantes foi do curso de Enfermagem $(n=46$; $58,2 \%)$, cursando entre $01^{\circ}$ ao $3^{\circ}$ período $(n=36 ; 45,6 \%)$, entre a faixa etária de 20 a 29 anos $(n=47 ; 55,7 \%)$, do sexo feminino $(n=64 ; 81,0 \%)$, com renda familiar 1 a 2 SM $(n=30 ; 38,0 \%)$, de Raça/Cor parda $(n=34$; 43,0\%). A maior parte dos estudantes residem em Jaboatão dos Guararapes ( $n=38 ; 48,1 \%)$ e não possuem plano de saúde $(n=46 ; 58,2 \%)$. Conclusão: Observa-se que a automediação pode ser entendida como um constructo social multidimensional. Destaca-se assim, a importância de ações como as de educação e saúde para uma maior reflexão e desenvolvimento de novas abordagens sobre a realidade analisada.

Palavras-chave: Automedicação, Estudantes, Universidade, Perfil de saúde.

\begin{abstract}
Objective: To demonstrate the epidemiological profile of drug use by students at the health school of a private university center. Methods: This is a descriptive, cross-sectional study with a quantitative approach, carried out with students of health courses at a private university center in the northeast region of Brazil. As an instrument for data collection, a questionnaire was developed with (16) sixteen questions about the demographic, social and cultural characteristics related to self-medication. Results: It was evidenced that the highest frequency of participants were from the Nursing course $(n=46 ; 58.2 \%)$, attending between the 1 st and 3rd period ( $n=36 ; 45.6 \%)$, between the age group from 20 to 29 years old $(n=47 ; 55.7 \%)$, female $(n=64 ; 81.0 \%)$, with family income 1 to $2 \mathrm{MW}(\mathrm{n}=30 ; 38.0 \%)$, of Race /Brown color ( $n=34 ; 43.0 \%)$. Most students live in Jaboatão dos Guararapes ( $n=38 ; 48.1 \%)$ and do not have health insurance $(n=46 ; 58.2 \%)$. Conclusion: It is observed that self-medication can be understood as a multidimensional social construct. Thus, the importance of actions such as education and health for greater reflection and development of new approaches to the analyzed reality is highlighted.
\end{abstract}

Keywords: Self-medication, Students, University, Health profile.

\section{RESUMEN}

Objetivo: Demostrar el perfil epidemiológico del consumo de drogas por estudiantes de la escuela de salud de un centro universitario privado. Métodos: Se trata de un estudio descriptivo, transversal con enfoque cuantitativo, realizado con estudiantes de cursos de salud en un centro universitario privado en la región noreste de Brasil. Como instrumento de recolección de datos, se desarrolló un cuestionario con (16) dieciséis preguntas sobre las características demográficas, sociales y culturales relacionadas con la automedicación. Resultados: Se evidenció que la mayor frecuencia de participantes fue del curso de Enfermería $(n=46$;

${ }^{1}$ Centro Universitário dos Guararapes (UNIFG), Jaboatão dos Guararapes - PE.

*E-mail: victormanuelps123@gmail.com

2 Instituto Aggeu Magalhães (IAM-FIOCRUZ), Recife - PE. 
$58,2 \%)$, cursando entre el 1er y 3er período ( $n=36 ; 45,6 \%)$, entre el grupo de edad de 20 a 29 años. edad ( $n$ $=47 ; 55,7 \%)$, mujer $(n=64 ; 81,0 \%)$, con ingresos familiares de 1 a $2 \mathrm{MW}(\mathrm{n}=30 ; 38,0 \%)$, de Raza / Color marrón ( $n=34 ; 43,0 \%)$. La mayoría de los estudiantes vive en Jaboatão dos Guararapes $(n=38 ; 48,1 \%)$ y no tiene seguro médico ( $n=46 ; 58,2 \%$ ). Conclusión: Se observa que la automedicación puede entenderse como un constructo social multidimensional. Así, se destaca la importancia de acciones como la educación y la salud para una mayor reflexión y desarrollo de nuevos enfoques a la realidad analizada.

Palabras clave: Automedicación, Estudiantes, Universidad, Perfil de salud.

\section{INTRODUÇÃO}

A automedicação é uma prática presente em diferentes culturas e diversas faixas etárias, que representa a atividade do indivíduo em selecionar e usar espontaneamente algum medicamento que considere conveniente para solução de um agravo de saúde (CORREIA CB, et al., 2019). Caracteriza-se, como uma maneira de autocuidado, sendo entendida como a seleção medicamentosa para a manutenção, prevenção e tratamento sem a prescrição de um profissional (VERNIZES T e SILVA L, 2016).

Diversos fatores podem estar relacionados com essa prática. Estudos evidenciam a educação, família, sociedade, direito e disponibilidade de drogas como destaques (DILLES T, et al., 2011; FONTES STO, et al., 2019). A utilização indiscriminada, experiências exitosas, o simbolismo que os fármacos representam para a sociedade bem como a dificuldade de acesso as ações e serviços de saúde também podem contribuir para a problemática (TARLEY MGG, et al., 2018; ALVES JED e CAVENAGHI S, 2012).

Apesar dessa prática estar associada a efeitos que possam trazer benéfico aos indivíduos, como a solução do problema, em muitos casos observa-se o desenvolvimento de reações prejudiciais a saúde, como as reações adversas, eventos adversos graves, resistência bacteriana, mascaramento de sinais e sintomas de patologias, entre outros (GALATO D, et al., 2012). Estudos também evidenciam que um dos riscos para o desenvolvimento dessa prática se relaciona ao nível de escolaridade, instrução e conhecimento acerca do uso de medicamentos (CHAVES ACTA, et al., 2016; LUKOVIC JA, et al., 2014).

Dados de uma com uma pesquisa realizada pelo Instituto de Ciência Tecnologia e Qualidade (ICTQ), demonstrou que o Brasil se configura como recordista mundial em automedicação, sendo que, mais de $70 \%$ dos brasileiros se automedicam. Além do alto índice, muitos têm o hábito de aumentar as dosagens para obter uma resposta mais acelerada (ICTQ, 2016). Em 2014, o mesmo instituto também apontou que quanto maior o grau de escolaridade, maior a automedicação pelos brasileiros (ICTQ, 2014).

O Sistema Nacional de Informações Tóxico-Farmacológicas (SINITOX), descreve que no Brasil mais de 25 mil casos de internação são registrados por ano devido a intoxicação por medicamentos (SANTOS GF, 2020). Outra fragilidade iminente da automedicação é que, quando administrado uma quantidade inadequada de fármacos ou quando usado várias classes de medicamentos, o risco potencial de se de mascarar sintomas de uma doença caracterizada como grave é elevado (FONTES STO, et al., 2019).

Segundo a Organização Mundial da Saúde (OMS) e o Ministério da Saúde (MS), o mercado brasileiro dispõe de 32 mil medicamentos. Contudo, somente 420 são consideradas necessárias para tratar as mais diversas doenças. Esse dado levantado pelas instituições é o motivo pelo qual o Brasil encontra-se em sexto lugar entre os maiores países consumidores de medicamentos (SANTOS TS, et al., 2018).

Atualmente, as pesquisam tentam analisar os perfis que mais utilizam medicações, ficando cada vez mais evidente que os principais usuários são aqueles que possuem um maior grau de conhecimento (GALATO D, et al., 2012; CHAVES ACTA, et al., 2016). Configurando, a automedicação entre estudantes um importante problema de saúde pública (GAMA ASM e SECOLI SR, 2017).

O motivo dessa associação é multifatorial, sendo importante o desenvolvimento de estudos que investiguem sua relação, principalmente devido à responsabilidade que eles, como acadêmicos e futuros profissionais devem em relação sua conduta profissional (FERRAZ NM, et al., 2016). Nesse contexto, o presente estudo teve como objetivo evidenciar, epidemiologicamente o perfil da utilização de fármacos pelos estudantes da escola de saúde de um centro universitário privado. 


\section{MÉTODOS}

Trata-se de um estudo de caráter descritivo, transversal, com abordagem quantitativa realizado com os alunos dos cursos da escola de saúde de saúde de um centro universitário privado da região nordeste do Brasil. A instituição conta com diversos cursos na parte da graduação tradicional, entre os cursos, os da escola de saúde: Enfermagem, Fisioterapia, Biomedicina, Educação física, Estética e Cosmética, Farmácia, Nutrição, Psicologia e Serviço Social. Além disso, fazem parte da escola de saúde a escola técnica que consta com os cursos de Técnico em Nutrição, Técnico em Radiologia e Técnico em Enfermagem.

A amostra foi composta pelo corpo acadêmico dos discentes dos cursos da escola de saúde. Foram adotados como critério de inclusão todos os discentes regularmente matriculados e que estivessem cursando a partir do $1^{1}$ período do semestre vigente. Os critérios de exclusão foram para os discentes que, não tinham acesso ao uso de internet devido a necessidade para resposta ao formulário de coleta de dados e/ou aqueles que por sua vez tinham acesso, mas que por algum motivo acabou enviando o formulário com mais de uma resposta em falta.

A coleta de dados foi realizada através do preenchimento por parte dos alunos de um formulário online desenvolvido na plataforma "Google Docs" A utilização do questionário online justifica-se devido a atual pandemia do COVID-19 e a inexistência da possibilidade do contato com os alunos para o desenvolvimento de uma coleta física na instituição como recomenda as normas preconizadas pela OMS e Ministério da Saúde.

Para a realização da pesquisa primeiramente foi feito contato com os coordenadores dos cursos de saúde para encaminhamento do formulário aos representantes de turmas de cada curso e turma por meio das redes sociais explicando a finalidade e o objetivo da pesquisa solicitando a autorização para coleta de dados. Os participantes responderam ao formulário composto por (16) dezesseis perguntas, algumas socioeconômicas e outras socioculturais, com a finalidade de responder aos objetivos propostos.

As informações obtidas foram analisadas e compactadas no programa Microsoft Excel 2013 onde posteriormente foi montado um banco de dados para o desenvolvimento de tabelas e gráficos a fim de propiciar os dados percentuais sobre as questões levantadas. A pesquisa é regida pela resolução 466/2012 do Conselho Nasional de Saúde (CNS) e aprovada pelo Comitê de Ética da Faculdade Tiradentes de Jaboatão dos Guararapes (FTJG) com CAAE: 35784920.4.0000.8727 e número do parecer 4.624.637.

\section{RESULTADOS}

De acordo com os resultados, que descrevem a amostra desse estudo, foi evidenciado na sua totalidade uma alta prevalência com relação ao processo de automedicação entre os estudantes da escola de saúde do centro universitário, sendo que, dos 83 participantes da pesquisa mais da metade, 79 ( $n=95,2 \%)$ evidenciaram a prática da automedicação (Gráfico 1).

Gráfico 1 - Percentual de alunos dos cursos de saúde que se automedicam ou não na instituição, n=83.

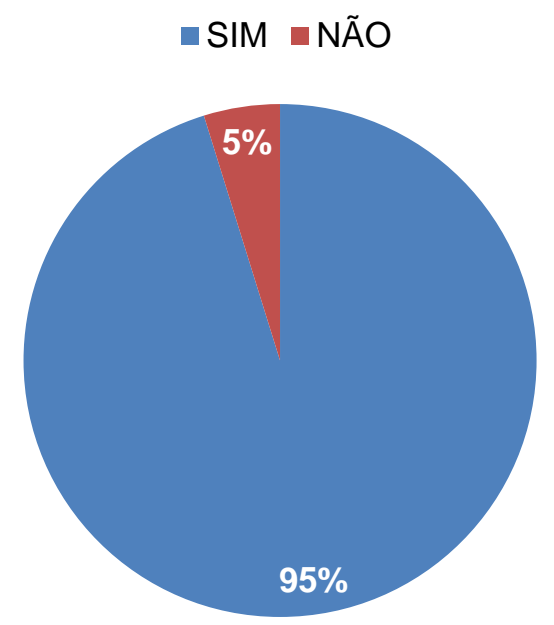

Fonte: Silva VMP, et al., 2021. 
A caracterização sociodemográfica mostrou que a maior frequência dos acadêmicos pertencia ao curso de Enfermagem $(n=46 ; 58,2 \%)$, cursando entre $01^{\circ}$ ao $3^{\circ}$ período $(n=36 ; 45,6 \%)$, entre a faixa etária de 20 a 29 anos $(n=44 ; 55,7 \%)$, do sexo feminino $(n=64 ; 81,0 \%)$, solteiro $(n=64 ; 81,0 \%)$, renda familiar 1 a 2 SM $(n=30 ; 38,0 \%)$, de Raça/Cor parda $(n=34 ; 43,0 \%)$. A maior parte dos estudantes residem em Jaboatão dos Guararapes ( $n=38 ; 48,1 \%)$ (Tabela 1).

Tabela 1 - Caracterização Sociodemográfica dos alunos dos cursos de saúde que se automedicam na instituição, $n=79$.

\begin{tabular}{|c|c|c|}
\hline Variável & (N) & $(\%)$ \\
\hline \multicolumn{3}{|l|}{ Curso } \\
\hline Biomedicina & 5 & 6,3 \\
\hline Educação Física & 2 & 2,5 \\
\hline Enfermagem & 46 & 58,2 \\
\hline Estética e Cosmética & 1 & 1,3 \\
\hline Farmácia & 2 & 2,5 \\
\hline Fisioterapia & 12 & 15,2 \\
\hline Nutrição & 2 & 2,5 \\
\hline Psicologia & 8 & 10,1 \\
\hline Serviço Social & 0 & 0,0 \\
\hline Técnico em Enfermagem & 0 & 0,0 \\
\hline Técnico em Nutrição & 1 & 1,3 \\
\hline Radiologia & 0 & 0,0 \\
\hline \multicolumn{3}{|l|}{ Período } \\
\hline $1^{\circ}$ ao $3^{\circ}$ & 36 & 45,6 \\
\hline $4^{\circ}$ ao $6^{\circ}$ & 12 & 15,2 \\
\hline $7^{\circ}$ ao $10^{\circ}$ & 31 & 39,2 \\
\hline \multicolumn{3}{|l|}{ Faixa Etária } \\
\hline $15-19$ & 17 & 21,5 \\
\hline $20-29$ & 44 & 55,7 \\
\hline $30-39$ & 10 & 12,7 \\
\hline $40-49$ & 8 & 10,1 \\
\hline 60 ou mais & 0 & 0,0 \\
\hline \multicolumn{3}{|l|}{ Sexo } \\
\hline Masculino & 15 & 19,0 \\
\hline Feminino & 64 & 81,0 \\
\hline \multicolumn{3}{|l|}{ Estado Civil } \\
\hline Casado & 14 & 17,7 \\
\hline Divorciado & 1 & 1,3 \\
\hline Solteiro & 64 & 81,0 \\
\hline Viúvo & 0 & 0,0 \\
\hline \multicolumn{3}{|l|}{ Renda Familiar } \\
\hline$<1 \mathrm{SM}$ & 19 & 24,1 \\
\hline 1 a 2 SM & 30 & 38,0 \\
\hline 2 a 3 SM & 15 & 19,0 \\
\hline 3 a 4 SM & 7 & 8,9 \\
\hline 5 a 6 SM & 4 & 5,1 \\
\hline$>6 \mathrm{SM}$ & 4 & 5,1 \\
\hline \multicolumn{3}{|l|}{ Raça/Cor } \\
\hline Branco & 28 & 35,4 \\
\hline Pardo & 34 & 43,0 \\
\hline Negro & 16 & 20,3 \\
\hline Amarelo & 1 & 1,3 \\
\hline Indígena & 0 & 0,0 \\
\hline \multicolumn{3}{|l|}{ Procedência } \\
\hline Jaboatão dos Guararapes & 38 & 48,1 \\
\hline Recife & 18 & 22,8 \\
\hline Interior & 13 & 16,5 \\
\hline Outras & 10 & 12,7 \\
\hline Total & 79 & 100 \\
\hline
\end{tabular}

Fonte: Silva VMP, et al., 2021. 
Sobre os dados de saúde, foi evidenciado que a maior parte dos estudantes não possuem plano de saúde ( $n=46 ; 58,2 \%$ ), estão cientes de que o uso de medicamentos sem prescrição médica pode causar sérios problemas de saúde pública, potencializar doenças e causar resistência microbiana $(n=77 ; 97,5 \%)$. A maioria dos estudantes, quando prescrito medicamento, costuma utilizá-lo até o final do tratamento indicado $(n=66$; $83,5 \%$ ) e não foram convidados a participar de algum evento envolvendo palestras sobre o risco do uso indiscriminado de fármacos $(n=65 ; 82,3 \%)$ (Tabela 2).

Tabela 2 - Caracterização dos dados de saúde dos alunos dos cursos de saúde que se automedicam na instituição, $n=79$.

\begin{tabular}{lcc}
\hline \multicolumn{1}{c}{ Variável } & (N) & (\%) \\
\hline Possui plano de saúde? & 33 & 41,8 \\
\hline Sim & 46 & \\
Não & \\
\hline E ciente de que o uso de medicamentos sem prescrição & \\
médica pode causar sérios problemas de saúde pública e & \\
potencializar doenças e causar resistência microbiana? & 77 \\
\hline Sim & 2 & 97,5 \\
Não & & \\
\hline Quando o médico receita um medicamento você costuma & \\
seguir a prescrição médica: & 12 \\
\hline Até acabar os sintomas & 66 & \\
Até o final dos dias prescritos & 1 & 15,2 \\
Não segue a prescrição médica & & 83,5 \\
\hline Já foi convidado a participar de algum evento envolvendo & 1,3 \\
palestras sobre o risco do uso indiscriminado de fármacos? & & \\
\hline Sim & 14 \\
Não & 65 & 17,7 \\
\hline Total & $\mathbf{7 9}$ \\
\hline
\end{tabular}

Fonte: Silva VMP, et al., 2021.

Os resultados a seguir descrevem o percentual direcionado a caracterização das classes dos medicamentos mais utilizados entre os estudantes. Os analgésicos se configuraram como a classe de medicamentos mais utilizada entre os estudantes $(n=57 ; 72,1 \%)$, seguidos dos antibióticos em segundo lugar com uma grande diferença percentual ( $n=11 ; 13,9 \%)$, tiveram maior prevalência (Gráfico 2).

Gráfico 2 - Caracterização dos medicamentos mais utilizados entre os alunos dos cursos de saúde que se automedicam na instituição, $n=79$.

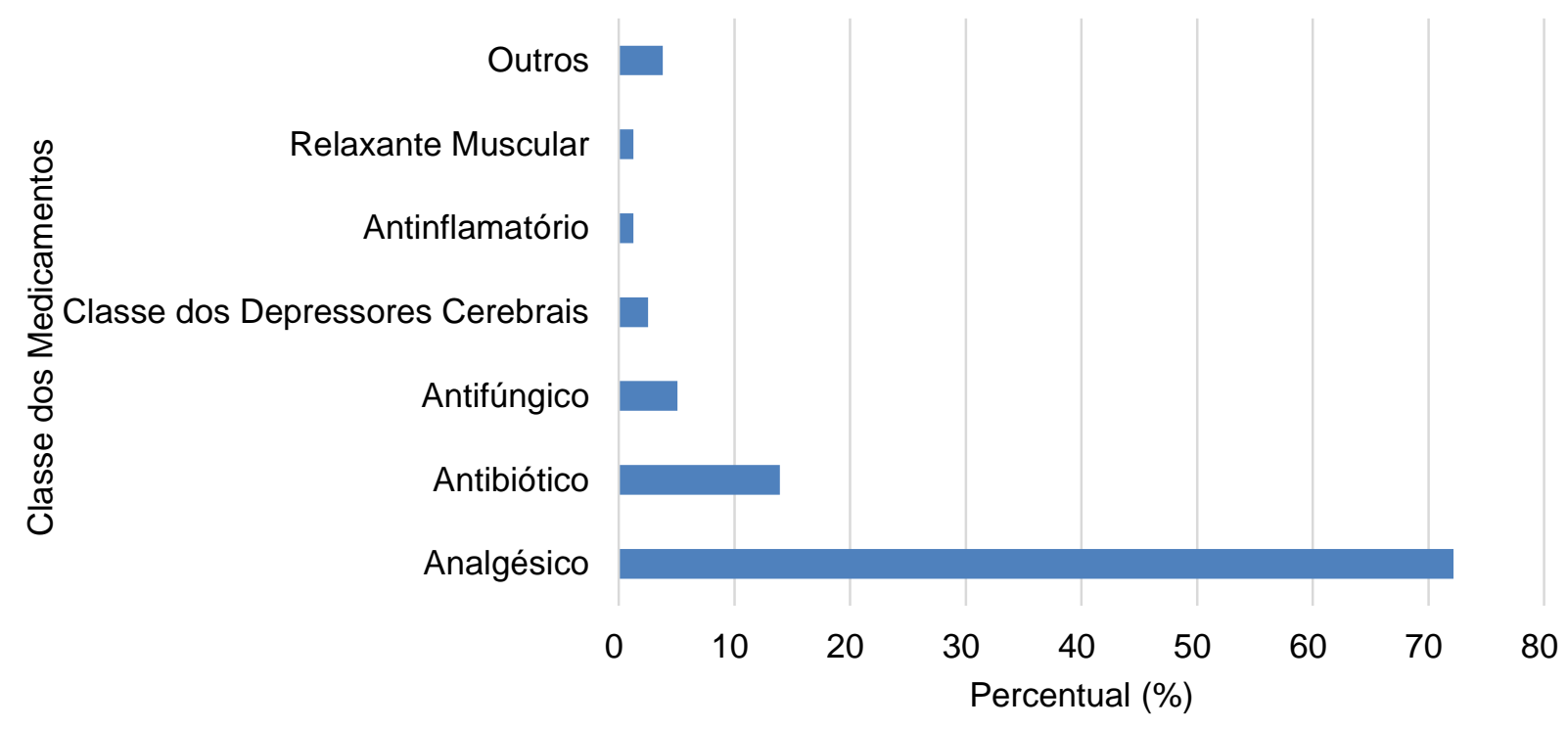

Fonte: Silva VMP, et al., 2021. 
Referente a frequência de uso foi observado que os estudantes não se medicavam de forma rotineira, com frequência média de uso uma vez por mês ( $n=57 ; 72,2 \%$ ). Nesse resultado em específico destaca-se um número e percentual de ignorados n: $4 ; 5,15 \%$ dos participantes que não marcaram nenhuma das alternativas presentes do formulário de coleta de dados (Gráfico 3).

Gráfico 3 - Caracterização da frequência de uso de medicamentos entre os alunos dos cursos de saúde que se automedicam na instituição, $n=75$.

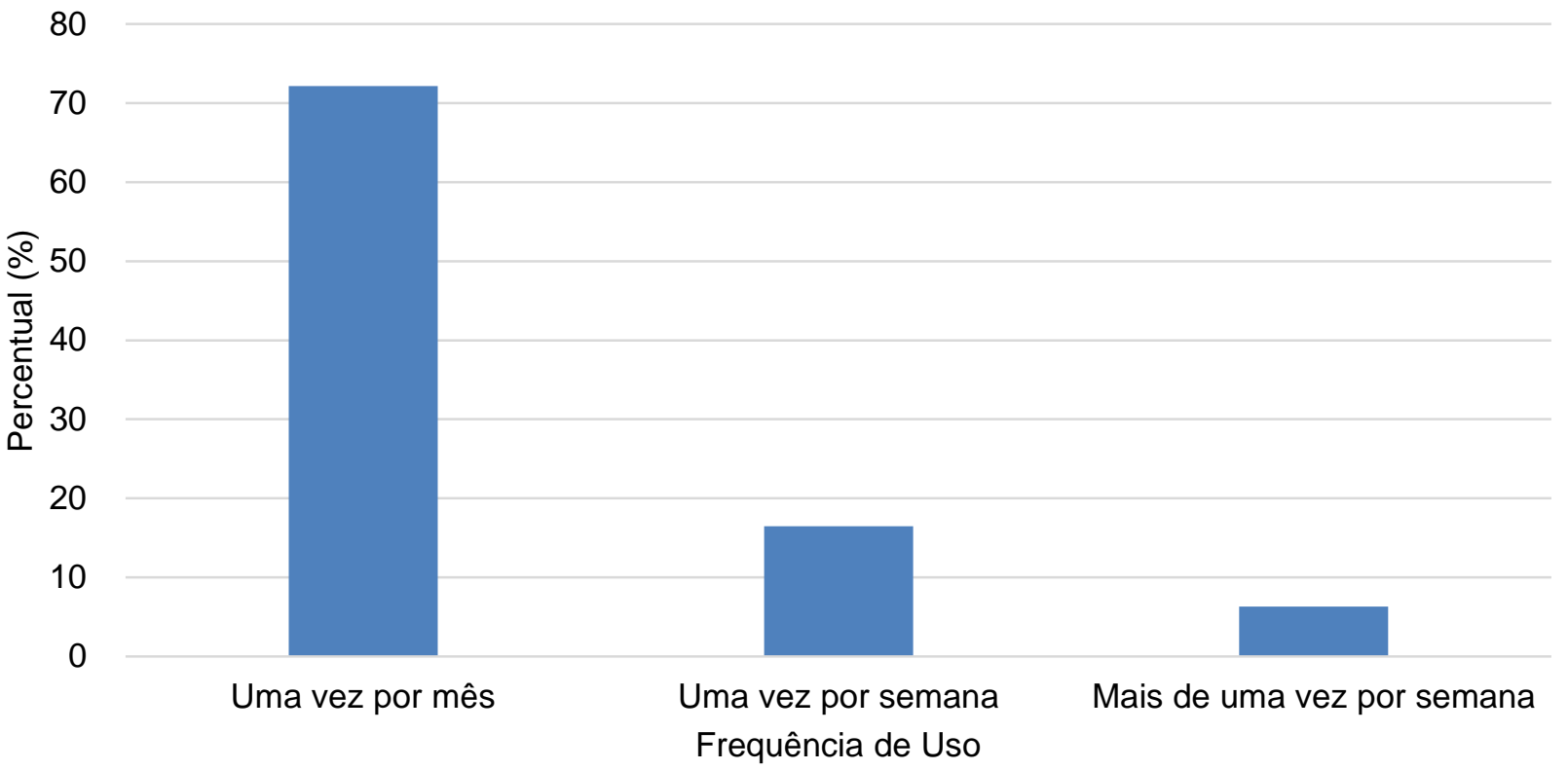

Fonte: Silva VMP, et al., 2021.

Sobre os motivos associados ao uso dos medicamentos a maior parte dos estudantes designaram usar devido o conhecimento prévio que tinham do fármaco $(n=49 ; 62,0 \%)$, seguidos de indicações de vizinhos, familiares, amigos, etc ( $n=17 ; 21,5 \%$ ), destaca-se um número e percentual de ignorados de participantes que não responderam à pergunta no formulário de coleta de dados em $\mathrm{n} ; 1 ; 1,3 \%$ (Gráfico 4).

Gráfico 4 - Caracterização quanto a motivação de uso dos medicamentos entre os alunos dos cursos de saúde que se automedicam na instituição, $n=78$.

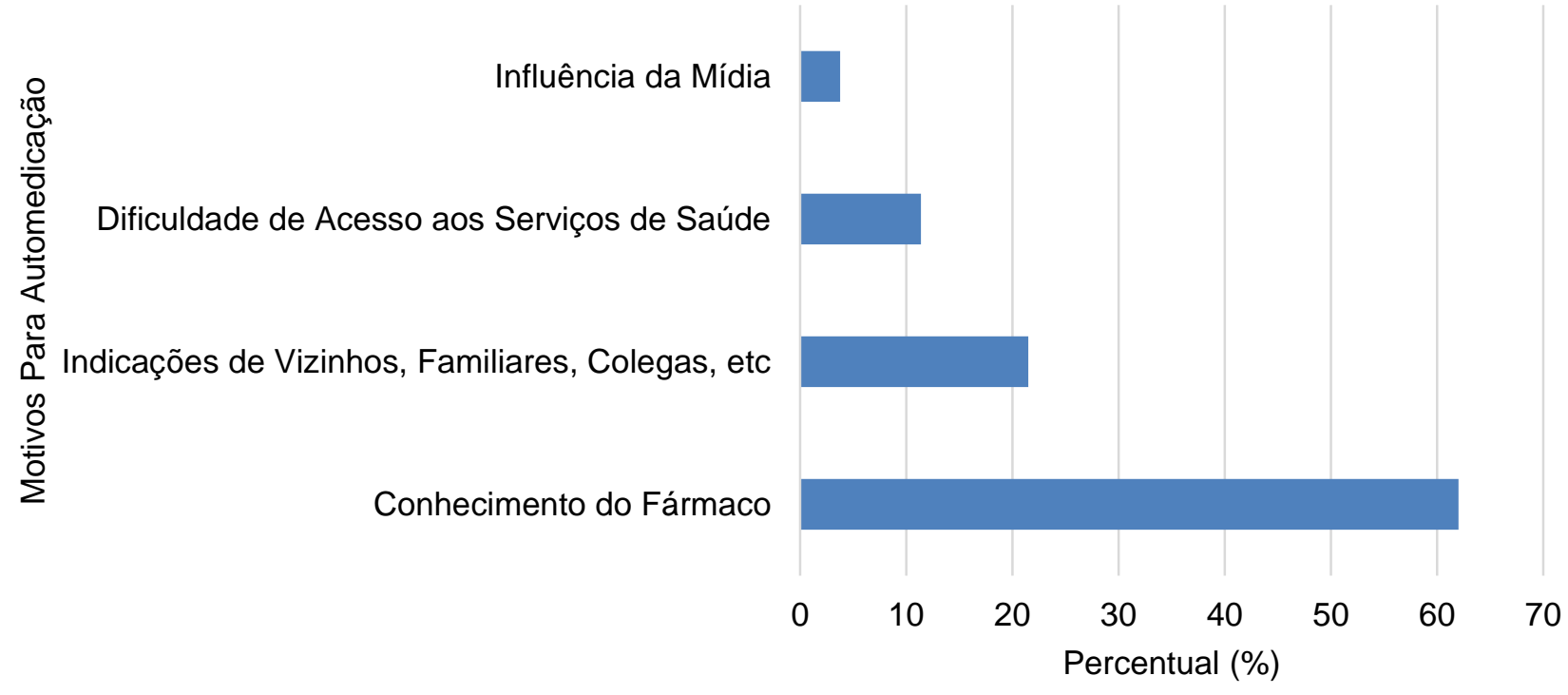

Fonte: Silva VMP, et al., 2021. 


\section{DISCUSSÃO}

Inicialmente, cabe destacar que quando se trata de estudantes universitários, sobretudo os da área da saúde, diversos estudos evidenciam um aumento da prática da automedicação ao longo do tempo (MARINHOS LN e MEIRELLES MA, 2021; TEIXEIRA KH, et al., 2020). O fácil acesso de fármacos, contato com profissionais da área da saúde, autoconfiança direcionado ao conhecimento teórico e prático adquirido durante a graduação e a falta de tempo para procurar assistência médica se destacam entre as principais relações abordadas na literatura com a temática (TARLEY MGG, et al., 2018; JESUS EMS, et al., 2019).

O aumento no uso indiscriminado de medicamentos é um importante e preocupante problema de saúde pública, por trazer consigo uma série de consequências aos indivíduos expostos que podem ser mais graves do que a própria doença primária quando associada. Além disso, destaca-se o aumento nos custos de saúde, já que, a prática da automedicação incube em gastos para o manejo de problemas resultantes desta. Nesse sentido, os achados desse estudo corroboram com outras pesquisas realizadas que identificaram uma grande taxa de estudantes do curso de Enfermagem como detentores de um grande percentual de automedicação (OLIVEIRA BMC, et al., 2019; CHAVES ACTA, et al., 2016).

Estar nos primeiros períodos do curso e a automedicação se associam no sentido de que muitas vezes ter menos conhecimento sobre o estado de saúde e o acúmulo de conhecimento, seja ele adquirido nas instituições educacionais ou em experiências de vida refletem em uma maior necessidade do estudante em sanar os sintomas rapidamente (JESUS EMS, et al., 2019). Contudo, muitas vezes o alto grau de instrução dos universitários os faz sentir confiantes na escolha de determinado medicamento, refletindo no uso irracional e inadequado (FONTES STO, et al., 2019; MUNHOZ TN, 2012).

A faixa etária predominante demonstrou ser algo bastante recorrente na literatura, pois, muitos estão adentrando no curso superior com essa idade, logo após sua formação no ensino médio (ROSSE WJD, et al., 2011; SANTOS GF, 2020). A automedicação entre os estudantes mais jovens pode estar relacionada também com uma maior preocupação em resolver um agravo de saúde, e logo vão buscar uma maneira de tratar ou prevenir sintomas e doenças (SANTOS TS, et al., 2018).

Analisando a automedicação entre diferentes gêneros, observou-se neste estudo uma maior predominância no gênero feminino, que vai de encontro com os resultados obtidos em outras pesquisas (ABDI A, et al., 2018). Tal achado, pode estar aliado a um maior autocuidado em virtude das mulheres, de modo geral, serem mais atentas aos sinais e sintomas. Majoritariamente, o sexo masculino tende a procurar 0 sistema de saúde através da atenção especializada, e tem como resultado o agravamento do quadro em detrimento do retardamento do problema (SANTOS GF, 2020). Ademais, o fato de que as mulheres estão mais expostas a situações estressoras devido múltiplos papéis por elas assumidos, pode reforçar este comportamento (TARLEY MGG, et al., 2018).

No tocante ao estado civil não foi encontrado relação direta com a literatura sobre a automedicação. Contudo, a automedicação entre estudantes viúvos e ou em situação de separação quando associados a sintomas depressivos tendem a ter uma maior prevalência (MUNHOZ TN, 2012). A renda familiar média baixa dos alunos pode ser preditor para a dificuldade de acesso aos serviços de saúde e ao profissional prescritor uma vez que a saúde enquanto direito universal ainda representa um desafio para o sistema de saúde brasileiro. Isto pode refletir na prática da automedicação visto que representa uma alternativa econômica e acessível, utilizada como primeira opção por indivíduos economicamente desfavoráveis (GAMA AS e SECOLI SR, 2017).

Em contraponto ao observado, pode-se observar na literatura que indivíduos com maior rendimento familiar, por sua vez, utilizam da automedicação por consequência de uma herança cultural bem como a facilidade de aquisição dos medicamentos dado seu poder aquisitivo o que direciona a compra de medicamentos, principalmente os amplamente divulgados pela mídia social (MARINHOS LN e MEIRELLES MA, 2021).

Em relação a Raça/Cor a maior parte dos estudantes evidenciou no formulário ser pardo, todavia não foi observado relação da automedicação com a variável. A raça/cor em si não é um fator de risco, e sim a inserção 
social adversa de um grupo racial/étnico constitui característica de vulnerabilidade (DILLES T, et al., 2011). Ademais, o fato que a maior parte evidenciar não ter plano de saúde pode se associar aos custos elevados da sua manutenção, que atrelado a ansiedade em acabar com os sintomas, dificuldade de acesso aos serviços e consequentemente o longo tempo de espera nas filas de atendimento favorecem a continuidade do entrave (TEIXEIRA KH, et al., 2020).

Quando perguntados se o uso de medicamentos sem prescrição médica poderia causar sérios problemas de saúde pública, potencializar doenças e causar resistência microbiana a grande maioria referiu-se que sim. É unânime na literatura que uso irracional de medicamentos pode proporcionar o agravamento de doenças previamente instaladas ou mascarando a sintomatologia dificultando consequentemente o diagnóstico precoce. Em casos da utilização de antibiótico, por exemplo, seu consumo abusivo pode levar a resistência de micro-organismos comprometendo o tratamento (FERREIRA BLS e OLIVEIRA TC, 2021). Referente aos dias do uso de medicamentos quando prescrito pelo médico a maioria costuma ingerir até o final dos dias prescritos. O uso de medicamentos durante o tempo prescrito é fundamental ao sucesso do tratamento, principalmente quando associado a outra classe medicamentosa (SILVA GGS, et al., 2020).

Dentro da graduação, os discentes da área da saúde na sua maioria das vezes possuem disciplinas que abordam os conhecimentos sobre os efeitos farmacológicos e os seus malefícios, fato este, que poderia atuar como um fator preventivo a prática da automedicação (FERRAZ NM, et al., 2016 e OLIVEIRA TC, 2021). No entanto, neste estudo foi evidenciado que a maior parte dos estudantes nunca foi convidado a participar de algum evento envolvendo palestras sobre o risco do uso indiscriminado de fármacos. Tal resultado, implica na importância do desenvolvimento de ações educativas que abordem a questão, em detrimento que muitas vezes a automedicação se configura devido falta de informações sobre seus malefícios a saúde e uma autoconfiança gerada através de se ter conhecimento prévio (SOUZA SN e LIMA CR, 2019).

Sobre as classes de medicamentos mais utilizadas no estudo, a literatura descreve que a facilidade de uso dos analgésicos deve-se ao seu enquadramento como Medicamentos Isentos de Prescrição (MIPs). Esses medicamentos considerados como tarja vermelha são livres de prescrição médica e indicados para doenças de maiores ocorrências de menor gravidade (MARINHOS LN e MEIRELLES MA, 2021). Considerados seguros e eficazes, esses medicamentos quando utilizados em grande quantidade podem acarretar efeitos nocivos à saúde (TARLEY MGG, et al., 2018; OLIVEIRA BMC, et al., 2019).

Atualmente no mercado farmacêutico existem mais 50 tipos de anti-inflamatórios não esteroides (AINES), utilizados no tratamento dos mais variados tipos de dor decorrente do processo inflamatório. A inflamação é um processo extremamente benéfico para organismo humano, compensando a quebra equilíbrio e repondo as necessidades tissular perdidas (ISRAEL ALM, 2016). Quando esse mecanismo de defesa e reparação é combatido sem nenhuma indicação o organismo reage de forma contrária, impedindo que o mesmo ocorra, ocasionando efeitos colaterais em decorrência do uso inadequado (SOUZA SN e LIMA CR, 2019)

As consequências do uso são diversas com destaques as hepatites medicamentosas, cronificação de dores, doenças renais, úlceras gástricas, gastrites e etc. (VERNIZES T e SILVA L, 2016). Outrossim, é que quanto maior número de medicamentos administrado simultaneamente maior as chances de efeitos adversos, reações anafiláticas e um risco potencial de mortalidade (SOUZA SN e LIMA CR, 2019). No contexto da rotina estudantil, esses tipos de fármacos demonstram ser uma forma prática e acessível para melhoria de queixas de dor como cólicas menstruais, sintoma característico do sexo feminino, que consequentemente leva a automedicação (FERREIRA BLS e OLIVEIRA TC, 2021).

Sobre o uso dos antibióticos, a resistência antimicrobiana é o principal fator relacionado ao uso indiscriminado de antimicrobianos, o que dificulta o tratamento de doenças, aumentando consequentemente a taxa de mortalidade de doenças bacterianas comuns e os gastos do sistema público de saúde relacionados a novas opções de tratamento (FERRAZ NM, et al., 2016). A resistência aos antibióticos é caracterizada como um processo onde o organismo deixa de ser afetado por um antimicrobiano no qual era sensível e se torna resistente, sendo a automedicação principal causa, o que reduz a eficiência e a capacidade de tratamento de algumas doenças infecciosas por este tipo de medicamento (VERNIZES T e SILVA L, 2016). 
A Agência Nacional de Vigilância Sanitária (ANVISA) proíbe a venda de antibióticos com ausência de receita médica. Estudos semelhantes ao resultado obtido com discentes de universidades da África e Ásia demonstraram também o uso de antibiótico ser um fator preocupante na prática da automedicação em estudantes dos cursos de saúde (KHAN SD, et al., 2021 e NIWANDINDA F, et al., 2020). Cabe ressaltar que especificamente nesses países a execução das normas de regularização são limitadas, tendo em vista a pouca capacidade de resolutividade dos governos e a grande comercialização indevida de antibióticos no mercado, representando o uso de antibiótico como uma prática acessível para solução de problemas de saúde semelhante a realidade encontrada no contexto estudado (KHAN SD, et al., 2021).

Paradoxalmente, foi observado uma baixa frequência com que os acadêmicos consomem medicamentos, na qual ao investigar esse fator, os acadêmicos referiram fazer uso uma vez por mês. Dessa forma, a automedicação apesar de ser existente demonstrou não ser uma prática rotineira.

Os principais motivos da realização da automedicação se direcionaram a ter um conhecimento prévio do fármaco visto sua utilização anterior. Uma experiência positiva com um medicamento reforça seu uso devido a confiança depositada nele na experiência em resolver um problema de saúde (ISRAEL ALM, 2016 e TEIXEIRA KH, et al., 2020). Além disso, o fato do indivíduo não entender a sua situação de adoecimento tratando-a com pouca significância ou já ter tido algum sintoma semelhante reforça seu vínculo em procurar recursos à automedicação (VERNIZES T e SILVA L, 2016; GAMA ASM e SECOLI SR, 2017).

\section{CONCLUSÃO}

Nesse contexto, observa-se que a automedicação pode ser entendida como um constructo social multidimensional, principalmente quando se trata de uma abordagem entre estudantes de saúde. As relações entre grau de conhecimento e automedicação se inter-relacionam na medida que muitas vezes quanto maior o conhecimento elevado será possibilidade do estudante usar um determinado medicamento sem prescrição, fato esse destacado no estudo. Assim, apesar do estudo retratar a realidade de uma instituição privada de ensino superior, evidencia-se que o perfil da automedicação seja semelhante aos descritos na literatura. Destaca-se a importância de ações como as de educação e saúde que se se configuram como essenciais para uma investigação e discussão dos fatores que contribuem para essa prática. Como contribuição o presente estudo se configura como indispensável a reflexão e referencial teórico para novas abordagens.

\section{REFERÊNCIAS}

1. ABDI A, et al. Prevalence of self-medication practice among health sciences students in Kermanshah, Iran. BMC pharmacology and Toxicology, 2018; 1-7.

2. ALVES JED, CAVENAGHI S. Tendências demográficas, dos domicílios e das famílias no brasil. Revista aparte: inclusão social em debate, 2012; 24:1-33.

3. CHAVES ACTA, et al. Perfil de automedicação entre estudantes de enfermagem. Revista de Inovação, Tecnologia e Ciências, 2016.

4. CORREIA CB, et al. Fatores correlacionados à automedicação entre os jovens e adultos: uma revisão integrativa da literatura. Revista de Iniciação Científica e Extensão, 2019; 1: 57-61.

5. DILLES T, et al. Nursing students' pharmacological knowledge and calculation skills: Ready for practice? Revista Nurse Educ Today, 2011; 31(5): 499-505.

6. FERRAZ NM, et al. Resistência Bacteriana nas infecções hospitalares. Revista UNIANDRADE, 2016; 17: 86-100.

7. FERREIRA BLS, OLIVEIRA TC. Resistência bacteriana e sua relação com o consumo incorreto de antibióticos. Revista Multidisciplinar em Saúde, 2021; 2: 48-48.

8. FONTES STO, et al. Análise da automedicação em estudantes dos cursos da área de saúde da UFCG-CES-Campus Cuité. Revista dspace, 2019.

9. GALATO D, et al. Automedicação em estudantes universitários: A influência da área de formação. Revista Ciência\& Saúde Coletiva, 2012; 17: 3323-3330.

10. GAMA ASM, SECOLI SR. Automedicação em estudantes de enfermagem do Estado do Amazonas-Brasil. Revista Gaúcha de Enfermagem, 2017.

11. INSTITUTO DE CIÊNCIA TECNOLOGIA E QUALIDADE (ICTQ). Pesquisa Automedicação no Brasil. 2014. Disponível em:http://www.ictq.com.br/pesquisa-do-ictq/353-indicacao-de-amigo-reforca-a-pratica-da-automedicacao. Acessado em 12 de dezembro de 2020. 
12. INSTITUTO DE CIÊNCIA TECNOLOGIA E QUALIDADE (ICTQ). Pesquisa Automedicação no Brasil. 2016. Disponível em: https://ictq.com.br/pesquisa-do-ictq/871-pesquisa-automedicacao-no-brasil-2018. Acessado em 12 de dezembro de 2020.

13. ISRAEL ALM. Atenção, dispensação e prescrição farmacêuticas em homeopatia. Revista bvsalud, 2016.

14. JESUS EMS, et al. Automedicação em estudantes de graduação em Farmácia: uma revisão narrativa. Repositório ufs, 2019.

15. KHAN SD, et al. Data on self-medication among healthcare students at Najran University, KSA. Bioinformation, 2021; 599-607.

16. LUKOVIC JA, et al. Self-Medication Practices and Risk Factors for SelfMedication among Medical Students in Belgrade, Serbia. Revista PLoS ONE, 2014.

17. MARINHOS LN, MEIRELLES LMA. Os riscos associados ao uso de medicamentos isentos de prescrição. Revista saúde multidisciplinar, 2021.

18. MUNHOZ TN. Prevalência e fatores associados à depressão em adultos: estudo de base populacional. Dissertação (Mestrado em Epidemiologia) - Departamento de Medicina Social Universidade Federal de Pelotas, Rio Grande do Sul, 2012; 2: 20-20.

19. NIWANDINDA F, et al. Patterns and practices of self-medication among students enrolled at Mbarara University of Science and Technology in Uganda. Integrated pharmacy research \& practice, 2020.

20. OLIVEIRA BMC, et al. Automedicação entre estudantes universitários. Revista Unicesumar, 2019.

21. ROSSE WJD, et al. Perfil da automedicação em acadêmicos do curso de farmácia da Univiçosa, Viçosa- MG. Revista Brasileira de Farmacia. 2011; 92(3): 186-190.

22. SANTOS TS, et al. Prática da automedicação entre acadêmicos do curso de enfermagem de uma instituição de ensino superior. Revista Scientia Plena, 2018.

23. SANTOS GF. Autocuidado em saúde sob a perspectiva do homem: um olhar sobre masculinidades. Repositório pucgoias, 2020.

24. SILVA GGS, et al. Importância do farmacêutico clínico na diminuição das interações medicamentosas ao paciente oncológico na unidade de terapia intensiva. Brazilian Journal of Health Review, 2020; 5: 15542-15556.

25. SOUZA SN, LIMA CR. Automedicação em acadêmicos de enfermagem em uma instituição de ensino superior de Maceió. Caderno de Graduação-Ciências Biológicas e da Saúde-UNIT-ALAGOAS, 2019.

26. TARLEY MGG, et al. Estudo comparativo do uso da automedicação entre universitários da área da saúde e universitários de outras áreas não relacionados à saúde na Universidade de Marília-SP. Brazilian Journal of Surgery and Clinical Research, 2018; 1: 22-27.

27. TEIXEIRA KH, et al. Self-medication: a study on motivational factors and consequences of this practice. Research, Society and Development, 2020; 9(8) e161985608-e161985608.

28. VERNIZES T, SILVA L. A prática de automedicação em adultos e idosos: Uma revisão de literatura. Revista Saúde e desenvolvimento. 2016. 